\title{
Molecular targeted therapies in metastatic melanoma
}

This article was published in the following Dove Press journal:

Pharmacogenomics and Personalized Medicine

6 June 2013

Number of times this article has been viewed

\author{
Rima Chakraborty' \\ Carilyn N Wieland ${ }^{2}$ \\ Nneka I Comfere ${ }^{2}$ \\ 'University of Missouri-Kansas City \\ Medical School, Kansas City, MO, \\ ${ }^{2}$ Departments of Dermatology and \\ Laboratory Medicine and Pathology, \\ Mayo Clinic, Rochester, MN, USA
}

\begin{abstract}
The advent of personalized medicine has ushered in a new era for cancer therapy with a significant impact on the management of advanced melanoma. Molecular targeted therapies have shown promise in the management of various malignancies, including melanoma, with lower toxicity profiles and better overall survival as compared with conventional therapy. The discovery of BRAF mutations in melanoma led to the development of BRAF inhibitors for the treatment of advanced melanoma. However, growing concerns over drug resistance to molecular targeted therapies including BRAF inhibitors, have spurred efforts to elucidate additional molecular targets for the treatment of advanced melanoma. In this review, we discuss the known molecular aberrations in melanoma, current and novel targeted approaches in its treatment, and drug resistance patterns.
\end{abstract}

Keywords: BRAF inhibitors, metastatic melanoma, personalized medicine

\section{Introduction}

Malignant melanoma is the fifth and sixth most common new skin cancer diagnosis in men and women, respectively, in the United States. Among the skin cancers, melanoma has the greatest metastatic potential, with metastatic disease occurring in $10 \%-15 \%$ of patients at diagnosis. ${ }^{1,2}$ Metastatic melanoma has a dismal prognosis, with a five-year overall survival of $15 \%$. Over the past 40 years, limited progress has been made in the treatment of metastatic melanoma through the use of chemotherapy, immunotherapy, biochemotherapy, and combinations thereof. ${ }^{3,4}$

Conventional chemotherapy with dacarbazine and temozolomide has yielded poor response rates of $7 \%-20 \%$ and a median survival of nine months, with mild toxicity profiles. ${ }^{5,6}$ Immunotherapies such as interleukin-2, while achieving durable responses (response rate 16\%, median duration of response 8.9 months) in metastatic melanoma, are associated with significant toxicity ${ }^{3}$ and offer limited options for effective and safe therapies for management of metastatic melanoma. ${ }^{7,8}$

Two new immunotherapeutic agents, ie, ipilimumab (recombinant, fully human IgG1 monoclonal antibody against cytotoxic T lymphocyte-associated antigen 4 [CTLA-4]) and anti-programmed cell death 1 [PD-1], show promise as potentially effective therapies with manageable side effect profiles in metastatic melanoma. Ipilimumab has an overall response rate of $10.9 \%$, and in those patients who respond, over half have a durable response. ${ }^{9,10}$ The major limitations are that at this time there is no way to predict these responders, and side effects include numerous immunemediated toxicities. A T cell regulator that functions similarly to CTLA-4 is PD- 1 . The PD-1 ligand allows tumors to evade the host immune response. PD-1 ligand antibodies
Correspondence: Nneka I Comfere Department of Dermatology, Mayo Clinic, 200 First St SW, Rochester, MN 55905, USA

Email comfere.nneka@mayo.edu 
have been shown to enhance tumor immune response in patients with melanoma. ${ }^{11}$ Other promising therapies include several angiogenesis-promoting molecules, such as vascular endothelial growth factor. ${ }^{12}$ In spite of recent advances in immune-based therapy, and given the absence of long-term remissions in the majority of treated patients, new treatments for metastatic melanoma are needed.

Recent advances in molecular biology and genomics have uncovered the molecular heterogeneity of tumors and facilitated a shift in anticancer therapy strategies from the traditional "one-size-fits-all" approach to an individualized approach to therapy. ${ }^{13,14}$ Key molecular drivers of tumor oncogenesis and mechanisms of tumor resistance have been uncovered, revealing the limitations of reliance solely on the clinical and pathological classification of tumors. This knowledge has resulted in the development of new treatment strategies that rely on therapy targeted towards identified functional genetic mutations, resulting in improved tumor response rates and relatively tolerable side effect profiles. ${ }^{15}$

The discovery of activating mutations in serine/threonine kinase, BRAF (v-raf murine sarcoma viral oncogene homolog B1) in 50\%-60\% of melanomas (superficial spreading type) in 2002 spurred investigations into the development of targeted therapies. This ultimately resulted in the approval of vemurafenib, a BRAF inhibitor, by the US Food and Drug Administration in August 2011 for the treatment of locally advanced/unresectable or metastatic BRAF-mutated malignant melanoma. ${ }^{16,17}$ The purpose of this review is to discuss the conventional and novel molecular targeted treatment approaches for the management of advanced melanoma and show the major drug resistance patterns associated with BRAF inhibitor therapies.

\section{Molecular pathogenesis of melanoma and implications for targeted therapy}

Melanoma is a heterogeneous disease reflected by its complex pathobiology. Recent advances in molecular genomic techniques have enabled the elucidation of functionally relevant cellular processes implicated in the oncogenesis of melanoma. Dysregulation of the cell growth cycle and signaling represent key mechanisms for tumor growth and persistence in melanoma and are the predominant molecular events in the majority of cases.

\section{Cell cycle changes}

Cell cycle dysregulation in melanoma represents one of the most important pathogenetic mechanisms for its oncogenesis, resulting in uncontrolled cellular proliferation. The most prominent molecular target is the CDKN2A locus (chromosome 9p21) that acts as a tumor suppressor in melanoma. Germline and somatic mutations in CDKN2A account for $10 \%-40 \%$ of familial melanoma, ${ }^{18}$ and $10 \%$ of all melanomas are familial in origin. ${ }^{19}$ The absolute risk for melanoma in individuals with the CDKN2A mutation is modulated by identifiable heritable traits (skin, hair, and eye color, large numbers of benign and atypical nevi, giant congenital nevi or a family history of melanoma) and environmental factors (history of sunlight exposure). ${ }^{20,21-24}$ In familial cases, the risk for development of melanoma by the age of 50 years is $50 \%$ in the United States, and $76 \%$ by the age of 80 years. ${ }^{25}$ In sporadic CDKN2A mutation carriers, the risk of melanoma is much lower, at $14 \%, 24 \%$, and $28 \%$ by the ages of 50,70 , and 80 years. ${ }^{26}$

CDKN2A encodes two distinct proteins, p16 ${ }^{\mathrm{INK} 4 \mathrm{~A}}$ and

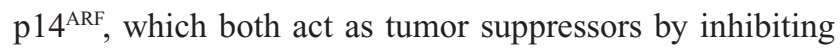
progression of the cell cycle through negative regulation of the RB1 and p53 pathways, respectively. Therefore, genetic aberrations that lead to functional loss of either of these proteins ( $\mathrm{p} 16^{\mathrm{INK} 4 \mathrm{~A}}$ and $\mathrm{p} 14^{\mathrm{ARF}}$ ) will ultimately result in uncontrolled cellular proliferation. While initial studies of first-generation CDK inhibitors, such as flavopiridol, failed to demonstrate efficacy in preclinical studies, second-generation CDK inhibitors (SCH 727965), have shown more promising results in halting melanoma progression in mouse xenografts. This effect is potentiated when CDK inhibitors are combined with paclitaxel..$^{27,28}$

RB1 is the central piece of the pathway controlled by $\mathrm{p} 16^{\mathrm{INK} 4 \mathrm{~A}}$, serving in its unphosphorylated form to sequester E2F transcription factor, preventing it from inducing gene expression critical for transition from the G1 to the $\mathrm{S}$ phase of the cell cycle. RB1 phosphorylation leads to release of $\mathrm{E} 2 \mathrm{~F}$, enabling it to induce expression of the target genes necessary for progression from the $\mathrm{G} 1$ to $\mathrm{S}$ phase of the cell cycle. Phosphorylation of RB1 is performed by a catalytic complex composed of cyclin D1 and CDK 4 or 6 . The activity of this catalytic complex is dependent on levels of $\mathrm{p} 16^{\mathrm{INK} 4 \mathrm{~A}}$. High levels of $\mathrm{p} 16^{\mathrm{INK} 4 \mathrm{~A}}$ lead to suppression of the activity of the cyclin D1-CDK4/6 complex, with resulting suppression of RB1 phosphorylation and suppression of release of EF2 sequestration and ultimately cell cycle arrest at the G1/S step. However, when levels of $\mathrm{p} 16^{\mathrm{INK} 4 \mathrm{~A}}$ are low, inhibition of the catalytic complex is released, resulting in progression of the cell cycle. Genetic mutations that affect the CDKN2A locus occur as deletions of $\mathrm{p} 16^{\mathrm{INK} 4 \mathrm{~A}}$ in $50 \%$ of melanomas and as inactivating point mutations in $9 \%$ of melanomas. ${ }^{29}$ 
This suggests that $\mathrm{p} 16^{\mathrm{INK} 4 \mathrm{~A}}$ serves a critical role in cell cycle regulation in melanocytes. Less common mutations include amplifications and point mutations of the CDK4 gene, resulting in constitutive activation of the CDK4/cyclin D1 complex, overexpression of CDK6, and inactivating mutations in the RB1 gene ( $6 \%$ of melanomas). ${ }^{29}$

TP53 is the most common gene mutation in human cancer and p53 transcription factor controls various genes responsible for cell cycle arrest, senescence, DNA repair, and cell death. However, TP53 mutations represent a low frequency event in melanoma, occurring in only $9 \%$ of melanomas. ${ }^{30}$ MDM2 is one of the negative regulators of p53 and is regulated by $\mathrm{p} 14^{\mathrm{ARF}}$ (one of the protein products of CDKN2A) which, when bound to MDM2, inhibits its function and stabilizes $\mathrm{p} 53 .{ }^{20}$ Mutations in p14 ${ }^{\mathrm{ARF}}$ result in restoration of MDM2 activity and ubiquitination of $\mathrm{p} 53$ by MDM2, with resulting degradation and destabilization of p53. ${ }^{31}$ This loss of $\mathrm{p} 53$ through mutations in p14 ${ }^{\mathrm{ARF}}$ and active MDM2 eventually leads to cell cycle progression. Therefore, the MDM2-p53 interaction is a possible treatment target for tumors because blocking MDM2 stabilizes and reactivates p53, allowing for tumor suppression. ${ }^{32}$ MDM2 antagonists are just beginning clinical trials.

\section{Cell signaling changes}

Dysregulation of the signal transduction pathway for mitogen-activated protein kinase (MAPK), also known as RAS/RAF/MEK, plays a key role in multiple human cancers, including melanoma. Activation of MAPK signaling by mutations is implicated in $90 \%$ of melanomas. ${ }^{33}$ Signaling through the MAPK pathway occurs through extracellular signals that lead to the binding of a broad array of receptor tyrosine kinases, which results in activation of Ras, a small G-protein with three isoforms, HRAS, KRAS, and NRAS, with resultant downstream effects of cellular proliferation and survival. Al-Mulla et al demonstrated the variable effects of Ras mutations on the invasiveness of tumors in vitro, with implications for the biologic behavior of these tumors in vivo. ${ }^{34}$ The receptor tyrosine kinases include growth factor receptors, such as epidermal growth factor receptor, c-KIT, platelet-derived growth factor receptor, vascular endothelial growth factor receptor, and fibroblast growth factor receptor. ${ }^{35}$ Binding of growth factors to receptor tyrosine kinases leads to activation of Ras, resulting in formation of a complex between Ras and one of the RAF serine/threonine kinase isoforms, ie, ARAF, BRAF, or RAF1 (CRAF). Formation of the Ras-RAF complex leads to activation of RAF and phosphorylation and activation of
MEK that, in turn, activates MAPK isoforms (also known as ERK), including MAPK3 and MAPK1. MAPK3 and MAPK1 activation results in an array of downstream effects, including increased proliferation, protection from apoptosis, and increased survival through induction of transcription factors and cell cycle proteins in the nucleus. ${ }^{20,35}$ Ras activation ultimately results in stimulation of multiple intracellular signaling pathways, including the MAPK pathway, Ral guanine nucleotide exchange factors, and the phosphoinositide 3-kinase (P13K/AKT) pathway. ${ }^{36}$

The predominant mutations in the MAPK pathway leading to its constitutive activation are mutations in BRAF. Of all malignancies, activating mutations in BRAF are present at the highest frequency $(27 \%-68 \%)$ in melanomas. ${ }^{16,37}$ The mutation that accounts for the majority $(60 \%-100 \%)$ of all BRAF mutations in melanoma involves substitution of a glutamate for valine at position $600(\mathrm{~V} 600 \mathrm{E}) .^{38,39}$ This results in downstream activation of MAPK and ultimately proliferation and survival of melanoma. Hence BRAF V600E represents an attractive molecular target for treatment of melanoma. The BRAF V600E mutation has also been described in benign melanocytic proliferations, suggesting that this mutational event alone is not sufficient for tumorigenesis and that additional genetic insults are required for transformation to melanoma. ${ }^{20}$ Intermittently sun-exposed skin, as well as acral and mucosal melanomas, commonly bear BRAF mutations. ${ }^{40}$ MAPK signaling in melanocytes via growth factor-mediated activation of adenylate cyclase primarily occurs through BRAF and likely explains the high frequency of BRAF mutations seen in melanoma. An increase in adenylate cyclase activity results in accumulation of cyclic AMP and activation of protein kinase. Activated protein kinase $\mathrm{A}$ inhibits $\mathrm{CRAF}$, enabling signaling to proceed via BRAF. ${ }^{41}$

Mutations in the Ras proteins, NRAS, HRAS, and KRAS, are less common events in melanoma, accounting for $20 \%$, $2 \%$, and $1 \%$ of all melanomas, respectively. These Ras mutations appear to represent early events in the oncogenesis of melanoma, with additional mutational events necessary to initiate oncogenic transformation. ${ }^{42}$ The most common $(>80 \%)$ mutation in NRAS is a point mutation that results in substitution of glutamine for leucine at position $61 .^{43}$ This point mutation leads to dysfunctional GTPase activity that maintains the Ras protein in an activated (GTP-bound) state. NRAS-mutated melanomas appear to have distinctive clinical, histopathologic, and prognostic features. The typical clinical presentation is in older individuals ( $>55$ years of age) on chronically photoexposed skin of the extremities. Histopathologic features include thicker tumors without 
ulceration and higher mitotic rates compared with BRAFmutant melanomas. Mutant NRAS melanoma has a worse overall survival than wild-type NRAS melanoma. ${ }^{44-46}$ Mutant NRAS melanoma is dependent on CRAF and not BRAF signaling for growth factor-mediated MAPK signaling. This pathway relies on two parallel mechanisms, including Ras isoform switching, that permits inactivation of BRAF by causing its phosphorylation thereby preventing Ras/BRAF association, and increased expression of the cyclic AMP degrading enzyme, phosphodiesterase IV, which restricts protein kinase A activity and ultimately prevents phosphorylation of CRAF at its inhibitory sites, promoting CRAFmediated MAPK signaling. ${ }^{41}$ The latter mechanism presents an opportunity for therapeutic targeting of phosphodiesterase IV through its inhibition in melanomas with Ras mutations that are resistant to BRAF V600E inhibitors. ${ }^{47}$ While phosphodiesterase IV antibodies have demonstrated therapeutic potential for the management of chronic obstructive pulmonary disease and asthma, ${ }^{48,49}$ there are no definitive studies evaluating their clinical efficacy in mutant NRAS or wildtype BRAF melanoma. However, preliminary findings have demonstrated inhibition of growth potential and increased apoptosis of mutant NRAS melanoma cell lines. ${ }^{47}$

\section{BRAF inhibitors: mechanisms of action and drug resistance patterns}

Recognition of multiple mutations in melanoma within components of the MAPK signaling pathway has led to interest in targeted therapies, especially given the lack of evidence for improved overall survival rates with conventional therapies, such as interleukin-2 and chemotherapy. ${ }^{50}$ While mutations in both NRAS and BRAF have been identified in melanoma, ${ }^{16,51}$ therapies targeting the MAPK pathway have focused on inhibition of BRAF and MEK. Initial attempts to inhibit BRAF in melanoma used sorafenib, a tyrosine kinase inhibitor that inhibits multiple tyrosine kinases, including BRAF. However, sorafenib does not block the V600E mutation, and therapy alone or in combination with chemotherapy did not demonstrate benefit. ${ }^{52-54}$ More selective BRAF inhibitors were developed, and in 2011 the US Food and Drug Administration approved the selective inhibitor, vemurafenib, for patients with malignant melanoma bearing the activating BRAF (V600E) mutation. In a Phase I trial, $81 \%$ of patients with V600E-positive metastatic melanoma responded to treatment. Overall, 26 of 32 patients showed a partial response (defined as a decrease by at least $30 \%$ in the sum of the largest diameter of each target lesion), including two with complete resolution. ${ }^{55}$ A randomized controlled Phase III trial compared vemurafenib with a commonly used standard chemotherapy agent, dacarbazine, in 675 patients with untreated V600E-positive metastatic melanoma. At six months, overall survival was $84 \%$ in the vemurafenib group and $64 \%$ in the dacarbazine group. ${ }^{17}$ After the interim analysis, crossover to vemurafenib from dacarbazine was recommended, and an updated analysis continues to show improvement in overall survival and progressionfree survival. ${ }^{17}$ While the initial response can be dramatic, progression-free survival has ranged from 5-7 months, ${ }^{17,57}$ leading to concern about drug resistance. Indeed, secondary mutations in addition to BRAF have been observed with progressive disease..$^{58,59}$

Dabrafenib is another selective BRAF inhibitor that has shown significant activity in patients with metastatic melanoma in Phase I/II studies. ${ }^{60}$ Further clinical trials are underway with dabrafenib. It is important to note that the BRAF inhibitors, vemurafenib and dabrafenib, are the first treatments to show benefit in patients with metastasis to the brain. ${ }^{61,62}$ In addition, while vemurafenib has been studied in patients with the V600E mutation, studies with dabrafenib are examining activity in non-V600E and V600K mutations. $^{56,62}$

Importantly, vemurafenib and dabrafenib have been well tolerated overall, with the most common side effects being cutaneous. Patients can experience fatigue and arthralgias with both agents, but unlike vemurafenib, approximately $10 \%$ of patients on dabrafenib also develop pyrexia. ${ }^{63}$ Patients can experience significant photosensitivity and rash that can require dose reduction, and epithelial neoplasms ranging from benign keratosis to keratoacanthomas and squamous cell carcinomas are common, and can affect up to $20 \%-30 \%$ of patients on vemurafenib. ${ }^{17,64}$ The mechanism underlying increased rates of malignant squamous proliferations with BRAF inhibitors is thought to involve disruption of the MAPK pathway, where inhibition of RAF activity leads to increased activity in RAS. RAS mutations are common in cutaneous squamous cell carcinomas and keratoacanthomas, and the paradoxical activation of RAS seen with BRAF inhibition accelerates the oncogenic process. ${ }^{65}$ There is also concern that BRAF inhibition may induce carcinogenesis in other melanocytic proliferations or other organs through a similar mechanism. For example, new wild-type BRAF primary melanomas have been found to arise in patients subsequent to treatment with BRAF inhibitors. ${ }^{66}$

Understanding drug resistance for selective BRAF inhibitors remains a major concern and area of interest. Although 
the pathway that leads to squamous cell carcinoma with BRAF inhibitors seems to have been elucidated, studies suggest resistance is due to more complex compensatory activation of numerous components of the MAPK pathway. There can be upregulation of receptor tyrosine kinases, such as platelet-derived growth factor receptor- $\beta$ and insulin-like growth factors, secondary NRAS mutations, and activation of MEK. ${ }^{58,59} \mathrm{MEK}$ activation can occur through various mutations in MEK $1 .{ }^{67}$ COT kinase is an activator of the MAPK pathway that does not require RAF signaling, and upregulation of COT kinase has been shown to promote resistance to BRAF inhibitors. ${ }^{68}$ In addition, increased phosophorylated ERK1/2 levels have been observed in melanomas with acquired resistance to vemurafenib. ${ }^{67}$ Finally, BRAF V600E splice variants, reported in colon and thyroid cancer, lead to reactivation of feedback in the MAPK pathway via MEK and the receptor tyrosine kinase, epidermal growth factor receptor. ${ }^{69-71}$ The possibilities for potential combinations allowing for drug resistance are clearly numerous and complex. These resistance patterns support consideration of combination therapies, including BRAF inhibitors and drugs that target other members of the MAPK pathway.

\section{Future directions in molecular- targeted therapy for melanoma}

With limited disease-free survival rates and drug resistance following treatment with BRAF inhibitors, additional treatment options are needed. Efforts are underway to find other targeted therapies within the MAPK pathway that could be used alone or in combination with BRAF inhibitors. There has been significant investigation into MEK inhibition. Phase III trials comparing trametinib, a MEK inhibitor, with chemotherapy in patients with BRAF V600E/K mutant malignant melanoma show improved overall survival and progressionfree survival. ${ }^{72}$ The combination of dabrafenib and trametinib has shown improved progression-free survival as well as reduction in the rate of secondary cutaneous neoplasms (such as squamous cell carcinoma). ${ }^{73}$ Based on the numerous pathways for resistance, MEK inhibition alone is unlikely to be the only answer to BRAF resistance. Nonetheless, MEK inhibitors have shown promise.

Another option being explored for targeted therapy in melanoma is the receptor tyrosine kinase, c-KIT (or CD117). Activating c-KIT mutations have been reported in approximately $20 \%-30 \%$ of certain subtypes of melanoma, including acral melanomas and mucosal melanomas, and melanomas that develop on photodamaged skin. ${ }^{74}$ The most common point mutation is $\mathrm{L} 576 \mathrm{P}$ in exon 11 , but point mutations also occur in exons 13,17 , and $18 .{ }^{75}$ Other tumors, including gastrointestinal stromal tumors with c-KIT mutations have been responsive to the tyrosine kinase inhibitor, imatinib. ${ }^{76}$ Therefore, Phase II trials were conducted with imatinib in patients with acral or mucosal melanoma or melanomas on chronically sun-damaged skin that harbored KIT mutations or amplifications. Response rates of $16 \%-23 \%$ with a small number of complete long-term responses have been seen, with no difference in response rates between the various melanoma subtypes. ${ }^{77-79}$ Notably, the same KIT mutations (K642E and N822K) that have shown response to treatment in gastrointestinal stromal tumors also show response in the treatment of melanoma. Meanwhile, resistance to specific KIT mutations (V654A and D820Y) are observed in both gastrointestinal stromal tumors and melanoma. ${ }^{77}$ There are numerous tyrosine kinase inhibitors, and trials involving other KIT-directed therapies are underway in patients with melanomas harboring c-KIT mutations.

Attempts have been made to target Ras indirectly by blocking important post-translation modification. Farnesyl transferase inhibitors, such as lonafarnib, block Ras by inhibiting its farnesylation and blocking translocation of Ras to the plasma membrane. Lonafarnib, in combination with other chemotherapeutic agents such as sorafenib and cisplatin, has demonstrated encouraging results in metastatic melanoma in vitro. ${ }^{80,81}$ A single clinical trial attempted to treat melanoma by inhibiting Ras via farnesyl transferase suppression, and showed significant toxicity and a lack of efficacy. ${ }^{82}$ However, it should be noted that the patients in this study were not selected based on the presence of NRAS mutation.

\section{Conclusion}

The advent of oncologic molecular typing has galvanized the discipline of personalized medicine. Recognition of common mutations within particular tumors has shown and holds tremendous promise for targeted individualized therapies. In melanoma, studies show an early favorable response to BRAF V600E inhibitors in treating BRAF V600E mutant melanomas. However, many challenges remain. The first and foremost is the other half of metastatic melanomas which do not harbor BRAF mutations. Another challenge is that although overall survival increases for those using BRAF inhibitors, complete resolution only occurs in a minority and most cases relapse through secondary resistance. Other targeted therapies, such as tyrosine kinase inhibitors, are being explored in melanomas with activating c-KIT mutations, and therapies such as MEK inhibitors are being developed to exploit regulation of the MAPK pathway. 
Immunomodulation has shown potential, but the ability to provide targeted immunomodulating therapy has yet to be achieved. The limitations of BRAF inhibitors and other targeted therapies reinforce the complexity of these tumors and the host response. Combinations of existing and new therapeutic options will need to be explored. However, advances made over the last few years have generated new hope for effective treatments.

\section{Disclosure}

The authors report no conflicts of interest in this work.

\section{References}

1. National Cancer Institute. A snapshot of melanoma, 2012. Available from: http://www.cancer.gov/researchandfunding/snapshots/pdf/ Melanoma-Snapshots.pdf. Accessed January 16, 2013.

2. National Cancer Institute. SEER Stats Facts sheets. Melanoma of the skin. Available from: http://seer.cancer.gov/statfacts/html/melan.html. Accessed April 16, 2013.

3. Eggermont AM, Schadendorf D. Melanoma and immunotherapy. Hematol Oncol Clin North Am. 2009;23:547-564.

4. Eggermont AM, Kirkwood JM. Re-evaluating the role of dacarbazine in metastatic melanoma: what have we learned in 30 years? Eur J Cancer. 2004;40:1825-1836.

5. Chapman PB, Einhorn LH, Meyers ML, et al. Phase III multicenter randomized trial of the Dartmouth regimen versus dacarbazine in patients with metastatic melanoma. J Clin Oncol. 1999;17:2745-2751.

6. Middleton MR, Grobb JJ, Aaronson N, et al. Randomized phase III study of temozolomide versus dacarbazine in the treatment of patients with advanced metastatic malignant melanoma. J Clin Oncol. 2000;18: $158-166$.

7. Atkins MB, Lotze MT, Dutcher JP, et al. High-dose recombinant interleukin-2 therapy for patients with metastatic melanoma: analysis of 270 patients treated between 1985 and 1993. J Clin Oncol. 1999;17:2105-2116.

8. Tsao H, Atkins MB, Sober AJ. Management of cutaneous melanoma. N Engl J Med. 2004;351:998-1012.

9. Hodi FS, O'Day SJ, MacDermott DF, et al. Improved survival with ipilimumab in patients with metastatic melanoma. $N$ Engl $J$ Med. 2010;363:711-723.

10. Robert C, Thomas L, Bondarenko I, et al. Ipilimumab plus dacarbazine for previously untreated metastatic melanoma. N Engl J Med. 2011;364: $2517-2526$

11. Brahmer JR, Tykodi SS, Chow LQ, et al. Safety and activity of antiPD-L1 antibody in patients with advanced cancer. $N$ Engl $J$ Med. 2012;366:2455-2465.

12. Dean E, Lorigan P. Advances in the management of melanoma: targeted therapy, immunotherapy and future directions. Expert Rev Anticancer Ther. 2012;12:1437-1448.

13. Midorikawa Y, Tsuji S, Takayama T, Aburatani H. Genomic approach towards personalized anti-cancer drug therapy. Pharmacogenomics. 2012;13:191-199.

14. Awada A, Vandone AM, Aftimos P. Personalized management of patients with solid cancers: moving from patient characteristics to tumor biology. Curr Opin Oncol. 2012;24:297-304.

15. Finn L, Markovic SN, Joseph RW. Therapy for metastatic melanoma: the past, the present and future. BMC Med. 2012;10:23.

16. Davies H, Bignell GR, Cox C, et al. Mutations of the BRAF gene in human cancer. Nature. 2002;417:949-954.

17. Chapman PB, Hauschild A, Robert C, et al; BRIM-3 Study Group. Improved survival with vemurafenib in melanoma with BRAF V600E mutation. N Engl J Med. 2011;364:2507-2516.
18. Goldstein AM, Chan M, Harland M, et al; Lund Melanoma Study Group, Melanoma Genetics Consortium (GenoMEL). Features associated with germline CDKN2A mutations: a GenoMEL study of melanoma-prone families from three continents. J Med Genet. 2007;44:99-106.

19. Meyer LJ, Zone JH. Genetics of cutaneous melanoma. $J$ Invest Dermatol. 1994;103(Suppl 5):112S-116S.

20. Sekulic A, Haluska P Jr, Miller AJ, et al; Melanoma Study Group of Mayo Clinic Cancer Center. Malignant melanoma in the 21st century: the emerging molecular landscape. Mayo Clin Proc. 2008;83:825-846.

21. Gilchrest BA, Eller MS, Geller AC, et al. The pathogenesis of melanoma induced by ultraviolet radiation. $N$ Engl J Med. 1999;340: $1341-1348$

22. Gandini S, Sera F, Cattaruzza MS, et al. Meta-analysis of risk factors for cutaneous melanoma: I. Common and atypical nevi. Eur J Cancer. 2005;41:28-44.

23. Tannous ZS, Mihm MC Jr, Sober AJ, Duncan LM. Congenital melanocytic nevi: clinical and histopathologic features, risk of melanoma, and clinical management. J Am Acad Dermatol. 2005;52:197-203.

24. Watt AJ, Kotsis SV, Chung KC. Risk of melanoma arising in large congenital melanocytic nevi: a systematic review. Plast Reconstr Surg. 2004;113:1968-1974.

25. Bishop DT, Demenais F, Goldstein AM, et al. Melanoma Genetics Consortium. Geographical variation in the penetrance of CDKN2A mutations for melanoma. J Natl Cancer Inst. 2002;94:894-903.

26. Begg CB, Orlow I, Hummer AJ, et al; Genes Environment and Melanoma Study Group. Lifetime risk of melanoma in CDKN2A mutation carriers in a population-based sample. J Natl Cancer Inst. 2005;97:1507-1515.

27. Abdullah C, Wang X, Becker D. Expression analysis and molecular targeting of cyclin-dependent kinases in advanced melanoma. Cell Cycle. 2011;10:977-988.

28. Mann MB, Kaldis P. Cell cycle transitions and Cdk inhibition in melanoma therapy: cyclin' through the options. Cell Cycle. 2011;10:1349.

29. Bennett DC. How to make a melanoma: what do we know of the primary clonal events? Pigment Cell Melanoma Res. 2008;21:27-38.

30. Petitjean A, Mathe E, Kato S, et al. Impact of mutant p53functional properties on TP53 mutation patterns and tumor phenotype: lessons from recent developments in the IARC TP53 database. Hum Mutat. 2007;28:622-629.

31. Kamijo T, Weber JD, Zambetti G, Zindy F, Roussel MF, Sherr CJ. Functional and physical interactions of the ARF tumor suppressor with p53 and Mdm2. Proc Natl Acad Sci U S A. 1998;95:8292-8297.

32. Shangary S, Wang S. Targeting the MDM-p53 interaction for cancer therapy. Clin Cancer Res. 2008;14:5318-5324.

33. Nikolaou VA, Stratigos AJ, Flaherty KT, Tsao H. Melanoma: new insights and new therapies. J Invest Dermatol. 2012;132:854-863.

34. Al-Mulla F, MacKenzie EM. Differences in in vitro invasive capacity induced by differences in Ki-Ras protein mutations. J Pathol. 2001;195: 549-556.

35. Fecher LA, Amaravadi RK, Flaherty KT. The MAPK pathway in melanoma. Curr Opin Oncol. 2008;20:183-189.

36. Downward J. Targeting RAS signaling pathways in cancer therapy. Nat Rev Cancer. 2003;3:11-22.

37. Houben R, Becker JC, Kappel A, et al. Constitutive activation of the Ras-Raf signaling pathway in metastatic melanoma is associated with poor prognosis. J Carcinog. 2004;3:6.

38. Platz A, Egyhazi S, Ringborg U, Hansson J. Human cutaneous melanoma: a review of NRAS and BRAF mutation frequencies in relation to histogenetic subclass and body site. Mol Oncol. 2008;1: 395-405.

39. Sclafani F, Gullo G, Sheahan K, et al. BRAF mutations in melanoma and colorectal cancer: A single oncogenic mutation with different tumor phenotypes and clinical implications. Crit Rev Oncol Hematol. December 11, 2012. [Epub ahead of print.]

40. Long GV, Menzies AM, Nagrial AM, et al. Prognostic and clinicopathologic associations of oncogenic BRAF in metastatic melanoma. J Clin Oncol. 2011;29:1239-1246. 
41. Dumaz N, Hayward R, Martin J, et al. In melanoma, RAS mutations are accompanied by switching signaling from BRAF to CRAF and disrupted cyclic AMP signaling. Cancer Res. 2006;66:9483-9491.

42. Mooi WJ, Peeper DS. Oncogene-induced cell senescence - halting on the road to cancer. $N$ Engl J Med. 2006;355:1037-1046.

43. Fedorenko IV, Gibney GT, Smalley KS. NRAS mutant melanoma: biological behavior and future strategies for therapeutic management. Oncogene. October 15, 2012. [Epub ahead of print.]

44. Devitt B, Liu W, Salemi R, et al. Clinical outcome and pathological features associated with NRAS mutation in cutaneous melanoma. Pigment Cell Melanoma Res. 2011;24:666-672.

45. Jakob JA, Bassett RL Jr, Ng CS, et al. NRAS mutation status is an independent prognostic factor in metastatic melanoma. Cancer. 2012;118: 4014-4023.

46. Ellerhorst JA, Greene VR, Ekmekcioglu S, et al. Clinical correlates of NRAS and BRAF mutations in primary human melanoma. Clin Cancer Res. 2011;17:229-235.

47. Marquette A, André J, Bagot M, Bensussan A, Dumaz N. ERK and PDE4 cooperate to induce RAF isoform switching in melanoma. Nat Struct Mol Biol. 2011;18:584-591.

48. O’Byrne PM, Gauvreau G. Phosphodiesterase-4-inhibition in COPD. Lancet. 2009;374:665-667.

49. Ngkelo A, Adcock IM. New treatments for COPD. Curr Opin Pharmacol. April 18, 2013. [Epub ahead of print.]

50. Crosby T, Fish R, Coles B, Mason MD. Systemic treatments for metastatic cutaneous melanoma. Cochrane Database Syst Rev. 2000;2: CD001215.

51. Demunter A, Stas M, Degreef H, De Wolf-Peeters C, van den Oord JJ. Analysis of N-and K-ras mutations in the distinctive tumor progression phases of melanoma. J Invest Dermatol. 2001;117:1483-1489.

52. Eisen T, Ahmad T, Flaherty KT, et al. Sorafenib in advanced melanoma: a Phase II randomised discontinuation trial analysis. $\mathrm{Br} J$ Cancer. 2006;95:581-586.

53. McDermott DF, Sosman JA, et al. Double-blind randomized phase II study of the combination of sorafenib and dacarbazine in patients with advanced melanoma: a report from the 11715 Study Group. J Clin Oncol. 2008;26:2178-2185.

54. Hauschild A, Agarwala SS, Trefzer U, et al. Results of a phase III, randomized, placebo-controlled study of sorafenib in combination with carboplatin and paclitaxel as second-line treatment in patients with unresectable stage III or stage IV melanoma. J Clin Oncol. 2009;27:2823-2830.

55. Flaherty KT, Puzanov I, Kim KB, et al. Inhibition of mutated, activated BRAF in metastatic melanoma. N Engl J Med. 2010;363:809-819.

56. Chapman P, Hauschild A, Robert C. Updated overall survival (OS) results for BRIM-3, a Phase III randomized, open-label, multicenter trial comparing BRAF inhibitor vemurafenib (vem) with dacarbazine (DTIC) in previously untreated patients with BRAFV600E-mutated melanoma. J Clin Oncol. 2012;30 Suppl:Abstr 8502.

57. Sosman JA, Kim KB, Schuchter L, et al. Survival in BRAF V600mutant advanced melanoma treated with vemurafenib. $N$ Engl J Med. 2012;366:707-714.

58. Nazarian R, Shi H, Wang Q, et al. Melanomas acquire resistance to B-RAF (V600E) inhibition by RTK or N-RAS upregulation. Nature. 2010:468:973-977.

59. Wagle N, Emery C, Berger MF, et al. Dissecting therapeutic resistance to RAF inhibition in melanoma by tumor genomic profiling. J Clin Oncol. 2011;29:3085-3096.

60. Kefford R, Arkenau H, Brown MP, et al. Phase I/II study of dabrafenib, a selective inhibitor of oncogenic mutant BRAF kinase, in patients with metastatic melanoma and other solid tumors. J Clin Oncol. 2010;28 Suppl:Abstr 8503.

61. Kirkwood JM, Long GV, Tretzer U, et al. BREAK-MB: a Phase II study assessing overall intracranial response rate to dabrafenib (GSK2118436) in patient with BRAFV600E/K mutation-positive melanoma with brain metastases. J Clin Oncol. 2012;30 Suppl:Abstr 8501.
62. Dummer R, Rinderknecht J, Goldinger SM, et al. An open-label pilot study of vemurafenib in previously treated metastastic melanoma patients with brain metastases. J Clin Oncol. 2011;29 Suppl:Abstr 8548 .

63. Hauschild A, Grob JJ, Demidov LV, et al. Dabrafenib in BRAF-mutated metastatic melanoma: a multicentre, open-label, phase 3 randomised controlled trial. Lancet. 2012;380:358-365.

64. Chu EY, Wanat KA, Miller CJ, et al. Diverse cutaneous side effects associated with BRAF inhibitor therapy: a clinicopathologic study. J Am Acad Dermatol. 2012;67:1265-1272.

65. Su F, Viros A, Milagre C, et al. RAS mutations in cutaneous squamouscell carcinomas in patients treated with BRAF inhibitors. $N$ Engl J Med. 2012;366:207-215.

66. Zimmer L, Hillen U, Livingstone E, et al. Atypical melanocytic proliferations and new primary melanomas in patients with advanced melanoma undergoing selective BRAF inhibition. J Clin Oncol. 2012;30: 2375-2383.

67. Trunzer K, Pavlick AC, Schuchter L, et al. Pharmacodynamic effects and mechanisms of resistance to vemurafenib in patients with metastatic melanoma. J Clin Oncol. April 8, 2013. [Epub ahead of print.]

68. Johannessen CM, Boehm JS, Kim SY, et al. COT drives resistance to RAF inhibition through MAP kinase pathway reactivation. Nature. 2010;468:968-972.

69. Prahallad A, Sun C, Huang S, et al. Unresponsiveness of colon cancer to BRAF (V600E) inhibition through feedback activation of EGFR. Nature. 2012;483:100-103.

70. Seth R, Crook S, Ibrahem S, et al. Concomitant mutations and splice variants in KRAS and BRAF demonstrate complex peturbation of the Ras/Raf signaling pathway in advanced colorectal cancer. Gut. 2009;58: 1234-1241.

71. Baitei EY, Zou M, Al-Mohanna F, et al. Aberrant BRAF splicing as an alternative mechanism for oncogenic B-Raf activation in thyroid carcinoma. J Pathol. 2009;21:707-715.

72. Flaherty KT, Robert C, Hersey P, et al. Improved survival with MEK inhibition in BRAF-mutated melanoma. $N$ Engl J Med. 2012;367: 107-114.

73. Flaherty KT, Infante JR, Daud A, et al. Combined BRAF and MEK inhibition in melanoma with BRAF V600 mutations. $N$ Engl J Med. 2012;367:1694-1703.

74. Curtin JA, Busam K, Pinkel D, et al. Somatic activation of KIT in distinct subtypes of melanoma. J Clin Oncol. 2006;24:4340-4346.

75. Beadling C, Jacobson-Dunlop E, Hodi FS, et al. KIT gene mutations and copy number in melanoma subtypes. Clin Cancer Res. 2008;14: 6821-6828.

76. Demetri GD, von Mehren M, Blanke CD, et al. Efficacy and safety of imatinib mesylate in advanced gastrointestinal stromal tumors. $N$ Engl J Med. 2002;347:472-480.

77. Carvajal RD, Antonescu CR, Wolchok JD, et al. KIT as a therapeutic target in metastatic melanoma. JAMA. 2011;305:2327-2334.

78. Guo J, Si L, Kong Y, et al. Phase II, open-label, single-arm trial of imatinib mesylate in patients with metastatic melanoma harboring c-Kit mutation or amplification. J Clin Oncol. 2011;29: 2904-2909.

79. Hodi FS, Friedlander P, Corless CL, et al. Major response to imatinib mesylate in KIT-mutated melanoma. J Clin Oncol. 2008;26:2046-2051.

80. Smalley KS, Eisen TG. Farnesyl transferase inhibitor SCH66336 is cytostatic, pro-apoptotic and enhances chemosensitivity to cisplatin in melanoma cells. Int J Cancer. 2003;105:165-175.

81. Niessner H, Beck D, Sinnberg T, et al. The farnesyl transferase inhibitor lonafarnib inhibits mTOR signaling and enforces sorafenibinduced apoptosis in melanoma cells. J Invest Dermatol. 2011;131: 468-479.

82. Gajewski TF, Salama AKS, Niedzwiecki D, et al. Phase II study of the farnesyltransferase inhibitor R115777 in advanced melanoma (CALGB 500104). J Transl Med. 2012 Dec 10;10:246. 


\section{Publish your work in this journal}

Pharmacogenomics and Personalized Medicine is an international, peerreviewed, open access journal characterizing the influence of genotype on pharmacology leading to the development of personalized treatment programs and individualized drug selection for improved safety, efficacy and sustainability. This journal is indexed on the American Chemical
Society's Chemical Abstracts Service (CAS). The manuscript management system is completely online and includes a very quick and fair peer-review system, which is all easy to use. Visit http://www.dovepress. com/testimonials.php to read real quotes from published authors.

Submit your manuscript here: http://www.dovepress.com/pharmacogenomics-and-personalized-medicine-journal 